\title{
AHP BASED ACADEMIC PERFORMANCE SCORESHEET (APS) FOR HOLISTIC ASSESSMENT OF ACADEMICIAN ACHIEVEMENTS
}

\author{
Mohamad Rizza bin Othman* \\ Process System Eng. \& Env. Group (PSEEG) \\ Faculty of Chem. \& Nat. Resources Eng. \\ Universiti Malaysia Pahang, MALAYSIA \\ E-mail: rizza@ump.edu.my \\ Syamsul Bahari bin Abdullah \\ Oil \& Gas Technology Group (OGTG) \\ Faculty of Chem. \& Nat. Resources Eng. \\ Universiti Malaysia Pahang, MALAYSIA \\ E-mail: syamsul@ump.edu.my
}

\begin{abstract}
The current performance assessment used by Faculty of Chemical \& Natural Resources Engineering (FKKSA), UMP has few critiques. These include rigid assessment criteria and unjustifiable scoring system. In this paper, we proposed a novel academician performance scoresheet (APS) based on analytic hierarchy process (AHP) to evaluate the performance of academic staff in FKKSA. The APS evaluation is based on five basic criteria namely education, research, professional works, administration and social/voluntary works. These criteria are further expanded into specific activity that embed quantity and quality element. The scoring system in APS is based on the weights set using AHP. To show its efficacy an online system is developed, where insightful analysis and decision support show its superiority over the current evaluation approach. We hope that this new approach will assist university managements for transparent and justified evaluation of its academic members.
\end{abstract}

Keywords: Performance scoresheet; Analytical Hierarchy Process (AHP)

\section{Introduction}

Annual working target (AWT) has been used in Faculty of Chemical \& Natural Resources (FKKSA) Universiti Malaysia Pahang (UMP) as a tool to evaluate the achievements of its academic staffs. The elements within the AWT were linked to the faculty's key performance indicator (KPI). Indirectly, the performance of any academic staff is measured based on how much it able to deliver the faculty's KPI. Although it works well, but there are few points which makes the current assessment system unfavorable. Firstly, the current system does not consider other scope of work other than what have been declared in the KPI. Since the assessment elements were restricted, some of the activities done by the academicians were not considered as achievements although it benefits the academician, faculty and university. Such activities include book review, journal review, invited speaker, guest Professor, voluntary works, etc. Another critique comes from the scoring method. In current practice, the faculty management set a score based on deductive logic. Although simple and easy to use, it creates some discrepancies as the methodology to establish the score is not well defined.

\footnotetext{
${ }^{*}$ Corresponding author
} 
In this paper we develop a novel academician evaluation system, called academician performance scoresheet (APS) that embeds AHP for evaluating the achievements of university academician. The new approach will offer flexibility in defining the assessment element thus provides a more holistic evaluation. It also incorporates quantitative and qualitative evaluation. Furthermore, the score setting is based on hierarchical pairwise comparison approach. Through this we hope that the current AWT can be improvised and offer a more transparent and justified assessment.

\section{Assessment methodology}

\subsection{Problem decomposition}

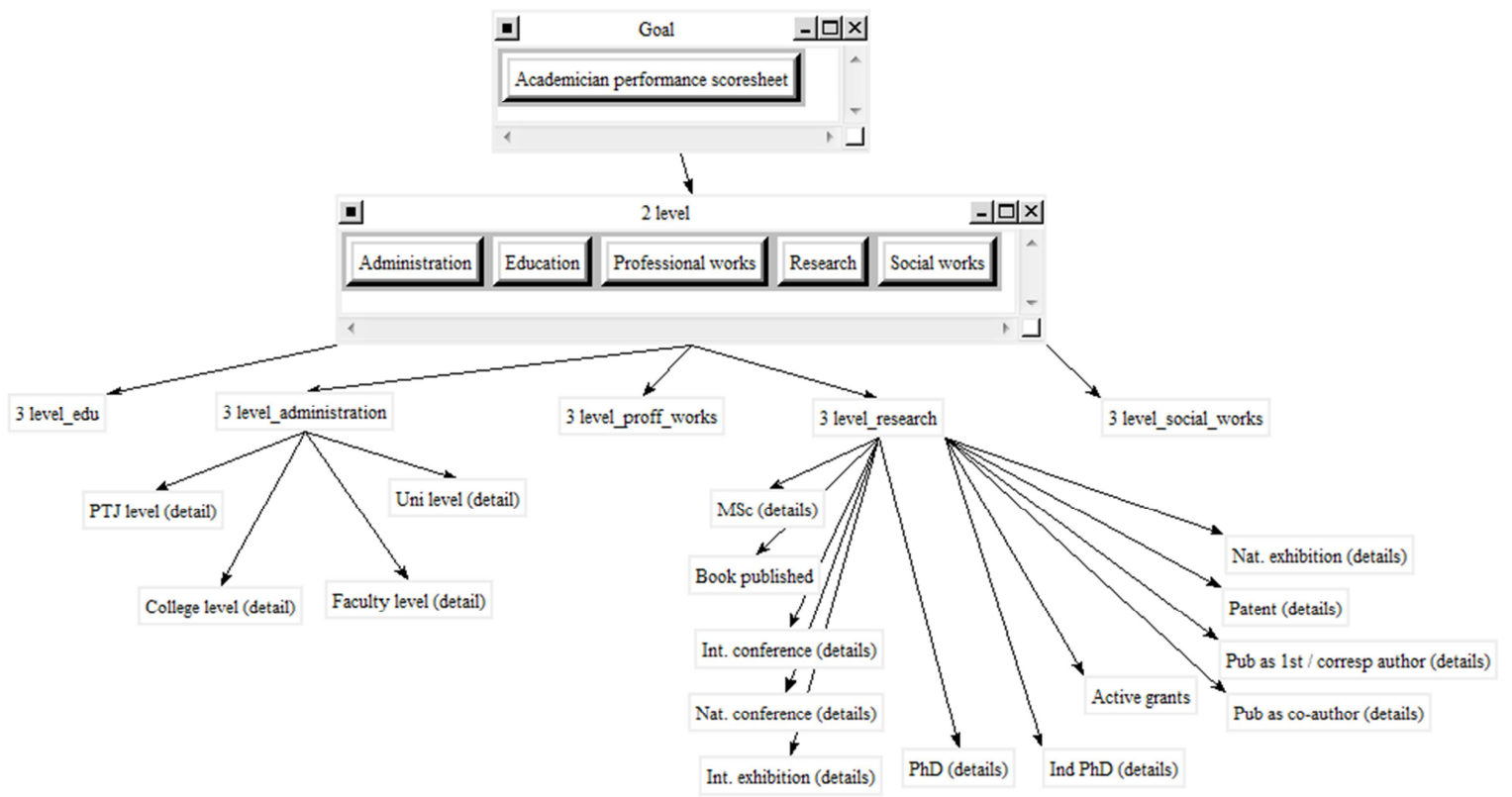

Figure 1. Decomposition of the problem hierarchy

University academician today demands multitasking work. Not only they involve in teaching and research but some may venture into other professional area i.e. consultation, paper review, social and voluntary work that benefit themselves and university (The Council, 2009; University of Cambridge Generic Role Profie, 2010a,b,c; Description of the occupation and duties of University Professors and Lecturers, 2013).

Based on this scenario, the proposed performance scoresheet to evaluate academician performance is categorized according to five criteria that act as a basis of assessment. The criteria include teaching and learning or education, research, professional works, administration and social/voluntary works. These criteria are further expanded into several levels such that at the bottom level, a specific tangible indicator is defined for each criterion. Figure 1 shows an overview of the problem hierarchy.

Note that, the indicators not only reflect the quantitative evaluation but also quality of their work. Take publication for example. In current practice, evaluation system in FKKSA does not differentiate between publications in non-indexed or indexed journals. Neither the system differentiates between first author and co-author or between submitted and published article. All publications, regardless of their quality, scored equally. The proposed system however, takes into account the quality of the publication activity. Different score are given to different set of publication activity. Below is an example of the relation 
between score and publication activity. The same rules apply to other activity such as conference presentation and exhibition participation.

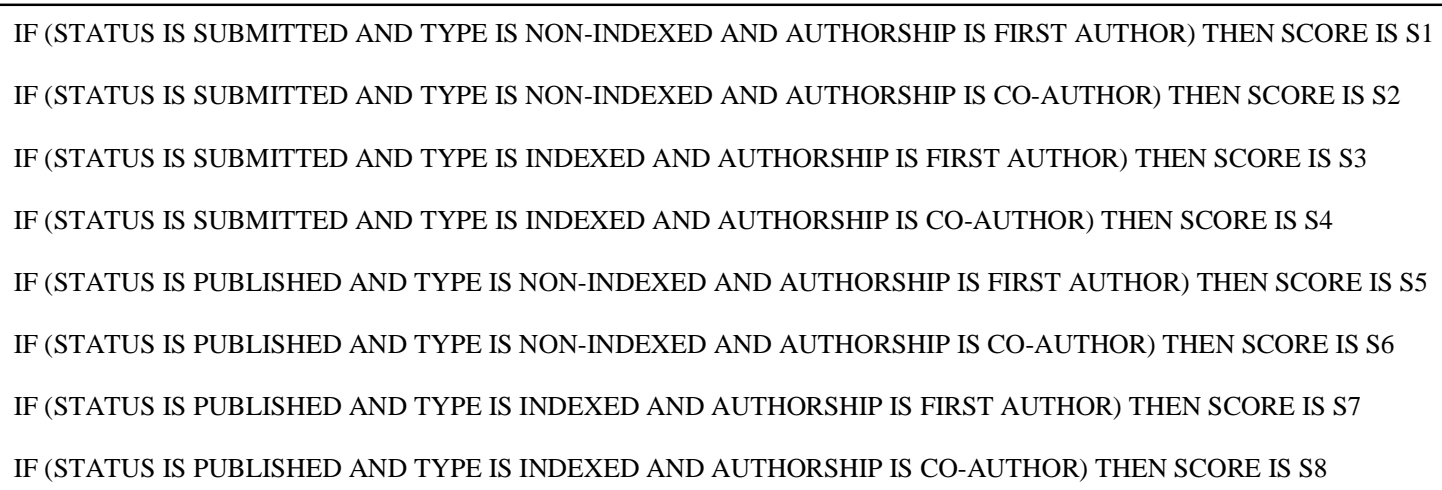

\subsection{Score setting}

The score setting is performed at the weighting step. A set of pair wise comparison matrices were constructed. Each pair is assigned with weight based on its perceived importance or relevance. Ranking step involve calculating the priorities based on the pairwise comparison matrices (Saaty, 2008). The priority value is use to indicate the score for each activity. Table 1 show an example of the normalized and idealized weights, and idealized score for activities in education section.

Table 1. Weights (normalized and idealized) and idealized score for activities in education section.

\begin{tabular}{|c|c|c|c|}
\hline Indicators & Normalized & Idealized & Idealized score, $\%$ \\
\hline 1.0 Education section & 0.344 & 0.344 & $\mathbf{3 4 . 3 8 8}$ \\
\hline 1.1 Academic and teaching awards received in 2012 & 0.008 & 0.008 & 0.762 \\
\hline Nom. academic award & 0.056 & 0.200 & 0.152 \\
\hline Nom. research award & 0.056 & 0.200 & 0.152 \\
\hline Nom. teaching award & 0.056 & 0.200 & 0.152 \\
\hline Rec. academic award & 0.278 & 1.000 & 0.762 \\
\hline Rec. research award & 0.278 & 1.000 & 0.762 \\
\hline Rec. teaching award & 0.278 & 1.000 & 0.762 \\
\hline 1.2 e-PAT score & $\mathbf{0 . 0 3 3}$ & $\mathbf{0 . 0 3 3}$ & 3.257 \\
\hline$<50 \%$ & 0.003 & 0.204 & 0.665 \\
\hline $50-69 \%$ & 0.005 & 0.343 & 1.116 \\
\hline $70-84 \%$ & 0.009 & 0.593 & 1.932 \\
\hline$>85 \%$ & 0.015 & 1.000 & 3.257 \\
\hline 1.3 Teaching workload & 0.100 & 0.100 & 9.990 \\
\hline$<100$ & 0.016 & 0.303 & 3.026 \\
\hline $100-210$ & 0.030 & 0.550 & 5.498 \\
\hline$>210$ & 0.054 & 1.000 & 9.990 \\
\hline 1.4 Teaching assessment workload & 0.100 & 0.100 & 9.990 \\
\hline$<100$ & 0.016 & 0.303 & 3.026 \\
\hline $100-250$ & 0.030 & 0.550 & 5.498 \\
\hline$>250$ & 0.054 & 1.000 & 9.990 \\
\hline 1.5 Number of URP students supervised & 0.032 & $\mathbf{0 . 0 3 2}$ & 3.187 \\
\hline 1.6 Number of PD group supervised & 0.042 & 0.042 & 4.160 \\
\hline 1.7 Number of subjects coordinated & 0.015 & 0.015 & 1.521 \\
\hline 1.8 Number of EAC documentation completed & 0.015 & 0.015 & 1.521 \\
\hline
\end{tabular}




\subsection{Index number calculation}

The performance of academician is based on the index number. The index number for each criterion is calculated using the equation below.

$$
I_{c}=\sum_{i=1}^{n} s_{i, c} x_{i, c}
$$

Where $I$ denotes the index number for criteria $c$, while $s$ and $x$ denotes the idealized score and quantity achievement of indicator $i$ respectively. The total index, $I_{T}$ is calculated by summation of all five criteria.

$$
I_{T}=\sum_{c=1}^{m} I_{c}
$$

\subsection{Assessment workflow}

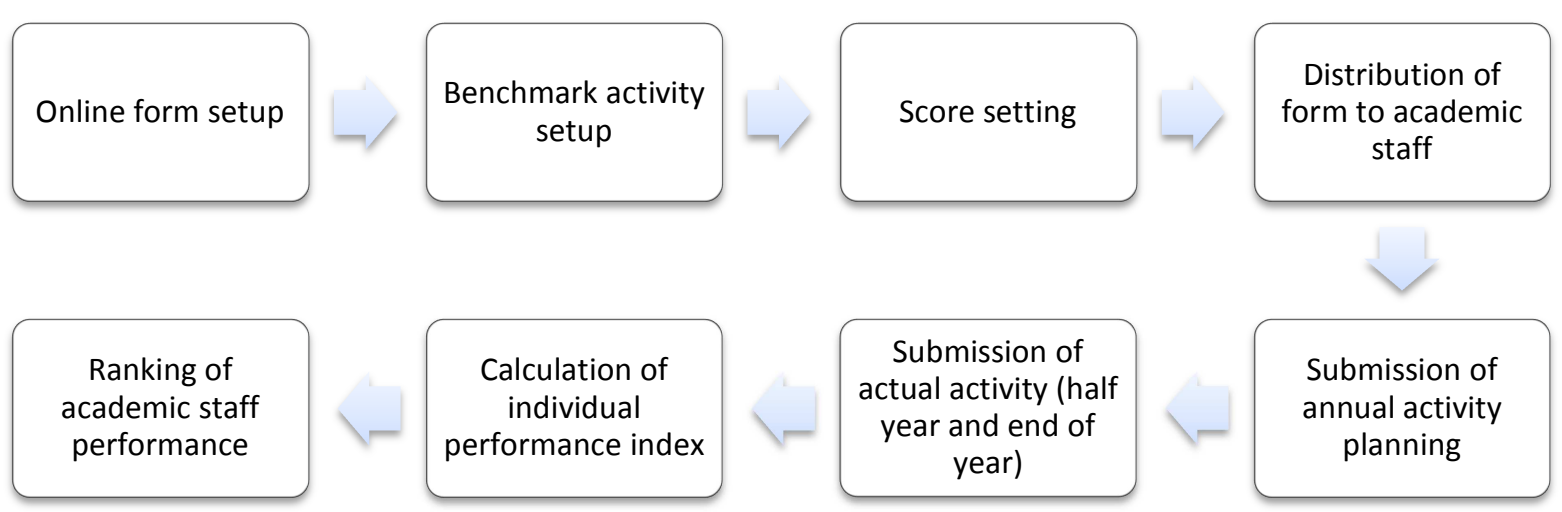

Figure 2. Performance evaluation workflow

Figure 2 shows the assessment workflow for the APS system. The first stage is development of an online form that capable of online and offline data entry. In this work, the form is developed using Adobe®Formscentral. Interesting features of this software are their capabilities to create forms as a writeable PDF, allow respondents to download PDF, print out, and save it in centralize database using cloud computing. The developed form is shown in Figure 3.

After setting up the form, the benchmark activities need to be setup. In this stage, we call a meeting with the top faculty management discussing the benchmark activities for academic staff. These activities also reflect the KPI of the faculty. The meeting also sets the score for each activity through pairwise comparisons. Subsequently, the form is distributed to all academic staff. They then need to key in the activity which they planned to execute over the year and submit it online. Update is done throughout the year which they need to submit the form again on half and end of a year. A dedicated APS team will calculate the performance index using tool develop in Excel. Once the entire performance index for each academic staff has been calculated, the academic staff achievements are ranked where it can be used to select individual for excellence service award given each year. 


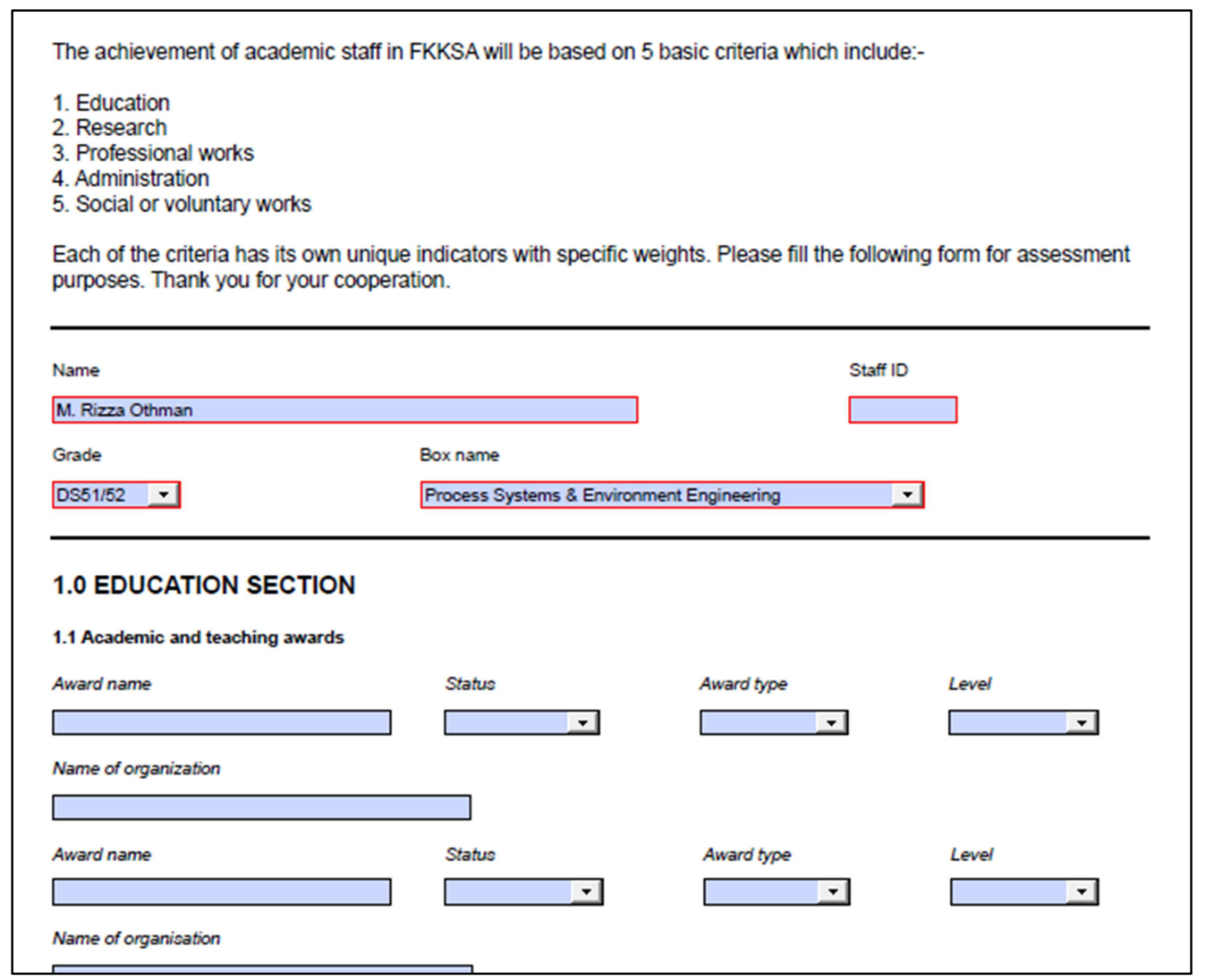

Figure 3. APS online data entry form using Adobe ${ }^{\circledR}$ Formscentral

\section{APS system and assessment results}

\subsection{Benchmark activity}

Table 2 shows the benchmark activities related to education section including activities by three academic staff in 2012. The activities will be filled in the data entry form. The application of online and offline system greatly simplifies the task for academic staff to fill up their activities for entire year. Moreover, it also helps the faculty management to monitor its academic staff performance and annual KPI.

Table 2. Example of benchmark activity and academic staff.

\begin{tabular}{|l|c|c|c|c|}
\hline Activity (Education section) & Benchmark & Mr. A & Mr. B & Mr. C \\
\hline 1.1 Academic and teaching awards received in 2012 & - & - & - & - \\
\hline 1.2 e-PAT score & $70-84 \%$ & $85-100 \%$ & $70-84 \%$ & $70-84 \%$ \\
\hline 1.3 Teaching workload & $100-210$ & $100-210$ & $<100$ & $100-210$ \\
\hline 1.4 Teaching assessment workload & $100-250$ & $100-250$ & $<100$ & $100-250$ \\
\hline 1.5 Number of URP students supervised & 5 & 3 & 3 & 3 \\
\hline 1.6 Number of PD group supervised & 1 & 1 & 1 & 1 \\
\hline 1.7 Number of subjects coordinated & 1 & 2 & 1 & 1 \\
\hline 1.8 Number of EAC documentation completed & 2 & 3 & 2 & 2 \\
\hline
\end{tabular}




\subsection{APS results}

Figure 4 shows the performance index for education section of three individuals which are compared to the benchmark activity. Note that the education performance is based on the activity listed in Table 2 . The result not only highlights the ranking of each individual but addressed the performance of each activity in detail. Assessors or superiors can thus identify the strengths of their staff members and also their weak point which can be highlighted for improvement. For example, Mr. B has the lowest index for education. The main contribution for this is due to low teaching and teaching assessment workload. In contrary, Mr. A excels in education section since he able to meet most of all the benchmark activity.

Figure 5 shows the performance for each section and overall achievement. The result shows that the education section dominates most of the overall achievement index. For the current result, an equal weight is given to all five criteria. However, it may be unfair for those who actively involved in managerial work. Therefore, it is suggested to have a different set of benchmark activity and weights for those who involve in managerial work. In addition, these performance ranking allows the top faculty management to give justifiable reward or recommendation for improvements.

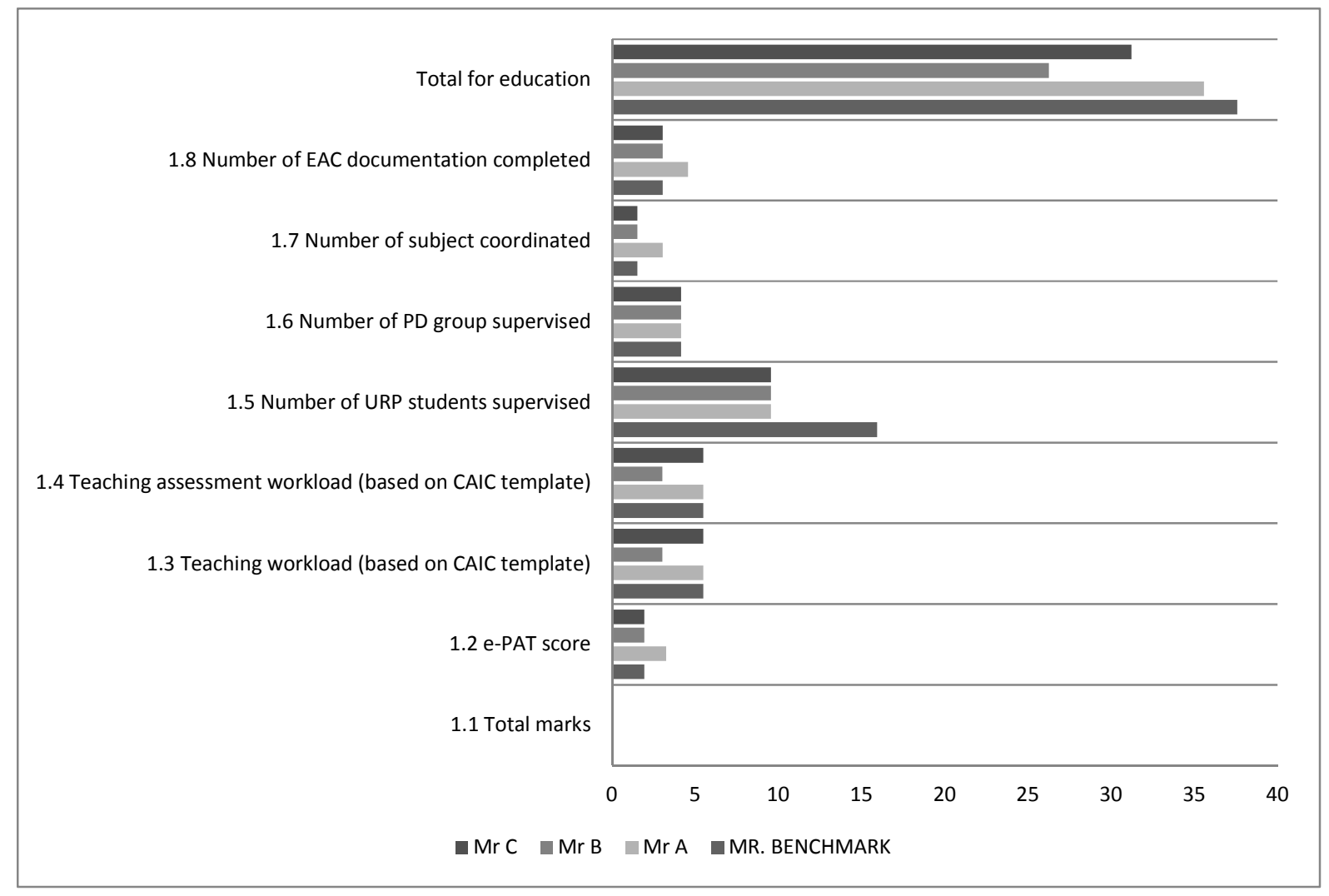

Figure 4. APS performance index for Education section. 
M.R. Othman, S.B. Abdullah/AHP Based Performance Scoresheet for Holistic Assessment of Academician Achievements

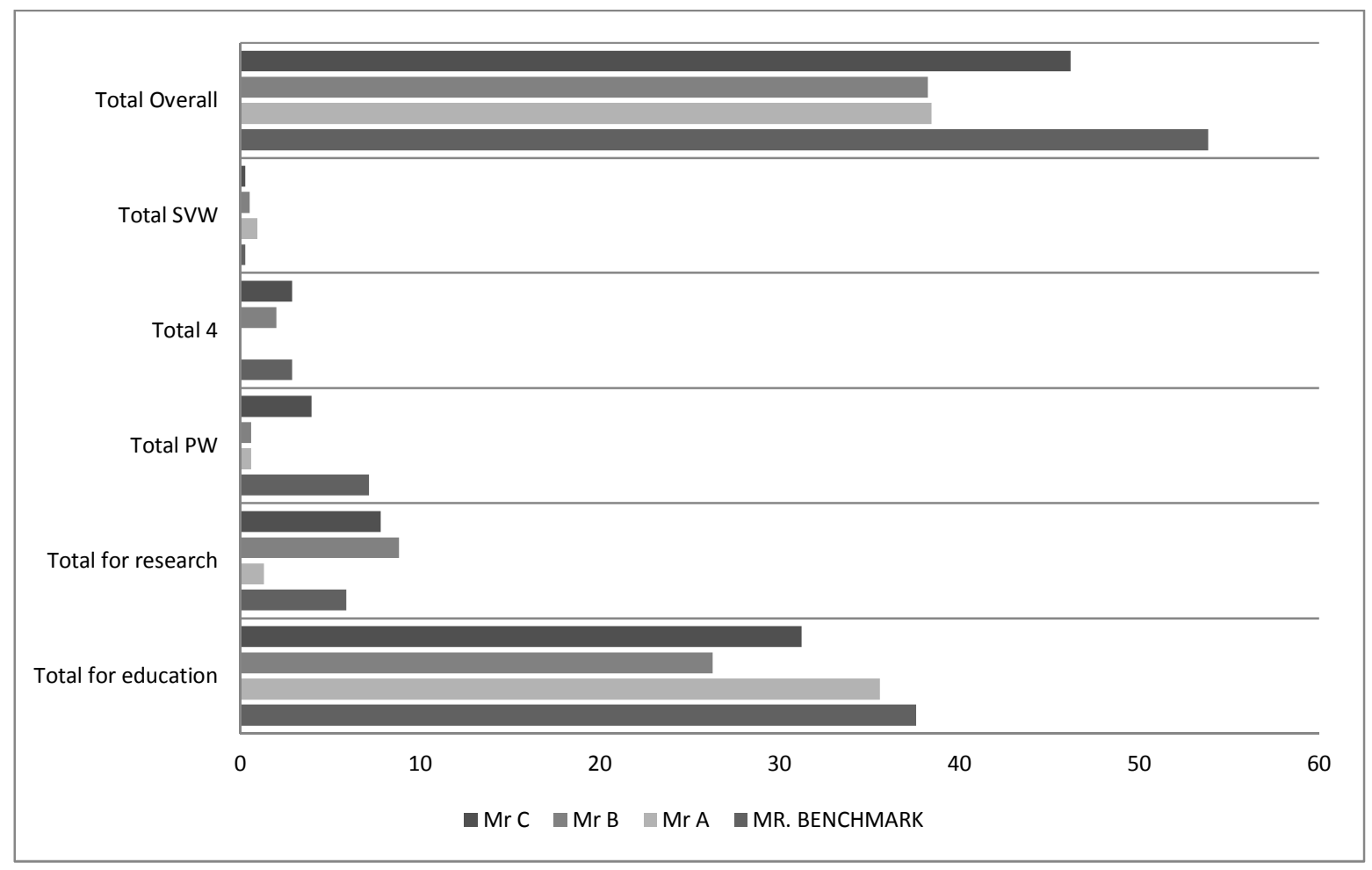

Figure 5. Results of overall performance index.

\section{Concluding remarks}

An academic performance scoresheet (APS) has been proposed to overcome the current implementation problem using AWT in FKKSA for assessing its academic staff. The main features of APS are its flexibility in specifying its evaluation indicator embedding both quality and quantity evaluation. Other than that, the scoring method in APS is based on weights setting using AHP which is more justified and systematic. The efficacy of the APS system has been demonstrated to three academic staff where insightful analysis and decision support show its superiority over the current evaluation approach. We hope that this new approach will assist university managements for holistic evaluation of its academic members using a simple yet transparent and justified assessment.

\section{Acknowledgements}

The authors would like to thank the top faculty management member of FKKSA for their support and cooperation.

\section{REFERENCES}

Description of the occupation and duties of University Professors and Lecturers. (2013). Retrieved from http://www.canadavisa.com/university-professors-4121.html. Access date 14 May 2013.

Saaty, T.L. (2008). Decision making with the analytic hierarchy process. Katz Graduate School of Business, University of Pittsburgh, Pittsburgh, USA. 
The Council. (2009). Academic Staff Performance Assessment Guidelines. Muhimbili University of Health and Applied Sciences.

University of Cambridge Generic Role Profile Professor. (2010a). Retrieved 14 $4^{\text {th }}$ May 2013, from http://www.admin.cam.ac.uk/offices/hr/grading/pd33/generic/usl.pdf.

University of Cambridge Generic Role Profile University Lecturer. (2010b). Retrieved $14^{\text {th }}$ May 2013, from http://www.admin.cam.ac.uk/offices/hr/grading/pd33/generic/ul.pdf.

University of Cambridge Generic Role Profile University Senior Lecturer. (2010c). Retrieved $14^{\text {th }}$ May 2013, from http://www.admin.cam.ac.uk/offices/hr/grading/pd33/generic/professor.pdf. 